\title{
Performance Analysis of Double Layer Stacked Patch Antenna with Edge Feed
}

\author{
J. Chandrasekhar Rao ${ }^{1}$ and A. K. Chaitanya ${ }^{2}$ \\ ${ }^{1}$ Assistant Professor, Department of ECE, St.Ann's College of Engineering \& \\ Technology, Chirala, A.P. India \\ ${ }^{2} P G$ student, Department of ECE, KL University, Vaddeswram, A.P. India \\ jettychandu@gmail.com
}

\begin{abstract}
In this paper a novel microstrip stacked patch antenna used for the Wireless LAN and Bluetooth applications is proposed. The proposed antenna is excited by using the edge feed and double layer dielectric substrate are used for enhancing the bandwidth and also for getting high gain of the antenna. The proposed antenna is simulated by using the HFSS software. The return loss up to $36.1 \mathrm{db}$ and gain $8.6 \mathrm{db}$ is obtained in the frequency range from $2.32 \mathrm{GHz}-2.38 \mathrm{GHz}$ with center frequency of $2.35 \mathrm{GHz}$. The VSWR $<1 \mathrm{~dB}$ at center frequency of $2.35 \mathrm{GHz}$ is obtained.
\end{abstract}

Keywords: Edge feed, Microstrip patch antenna, Stacked patch, Wireless LAN

\section{Introduction}

Microstrip antenna is one of the most useful antennas for wireless communication networks such as wireless LAN and Bluetooth which are operating at microwave frequencies $(f>1 \mathrm{GHz})$ because of its inherent advantages like low profile, light weight and easy fabrication. Microstrip antenna consists of a metal "patch" on one side of a dielectric substrate and ground plane and on the other side. The patch may be in a variety of shapes such as square, rectangular, circular and elliptical, but rectangular and circular are the most commonly used shapes [1]. Feeding techniques such as microstrip line feed, Aperture coupled feed and Proximity coupled feed are commonly used to feed the microstrip antennas. Narrow band width and spurious radiations are the drawbacks of microstrip antennas. These drawbacks can be solved by use of thicker substrates and multilayer structure. Different methods has been proposed to improve bandwidth, compact with high gain hence high transmission efficiency for wireless communication networks such as wireless LAN and Bluetooth [2-10].

A compact microstrip patch antenna in stacked configuration which reduces the patch area and at the same time enhances the gain and bandwidth with superstrate loading is proposed in [2]. A dual-polarized stacked microstrip antenna with two square patches is presented in [3]. In this configuration, one square patch of the microstrip antenna is fed diagonally by a microstrip line and another square patch with a superstrate is stacked above the corner-fed patch to increase the operating bandwidth. A planar antenna for wireless indoor network 
applications with radiation pattern diversity is proposed in [4]. This antenna structure is based on two tangential annular slot antennas etched on one side of a dielectric substrate and excited by electromagnetic coupling to microstrip feeding lines. The two-layer electromagnetically coupled rectangular patch antenna is presented in [5]. Two-layer elliptical microstrip stacked antenna based on circuit theory with coaxial fed, electromagnetically coupled is proposed in [6]. A stacked microstrip antenna with two parasitic elements is investigated experimentally for increasing impedance bandwidth and enhancing the gain [8]. Compact Stacked-Patch Antennas in LTCC multilayer packaging modules for Wireless Applications [9] and a parasitically coupled broadband patch antenna for the broadband wireless LAN application systems [10] are presented.

In this paper a double layer stacked rectangular microstrip patch antenna is proposed for wireless communication networks. The proposed antenna is excited by edge feed. Proposed antenna gives the good return loss of $36.1 \mathrm{~dB}$ with improved bandwidth and high gain at resonant frequency of $2.35 \mathrm{GHz}$.

The paper is organized as follows. Section 2 describes the microstrip antenna; simulation results and analysis of proposed antenna are given in Section 3.

\section{Microstrip Antenna Design}

Microstrip patch antenna consists of very thin metallic strip (patch) which is placed on ground plane where the thickness of the metallic strip is restricted by $\mathrm{t}<<\lambda_{0}$ and the height is restricted by $0.0003 \lambda_{0} \leq \mathrm{h} \leq .05 \lambda_{0}[2,5]$. The microstrip patch is designed in such a way that its radiation pattern maximum is normal to the patch. For a rectangular patch, the length $\mathrm{L}$ of the element is usually $\lambda_{0} / 3<\mathrm{L}<\lambda_{0} / 2$. There are numerous substrates that can be used for the design of microstrip antennas and their dielectric constants are usually in the range of $2.2 \leq \varepsilon_{\mathrm{r}}$ $\leq 12$. To fabricate the microstrip antennas, FR-4 $\left(\varepsilon_{\mathrm{r}}=4.9\right)$, Rogers TMM 4( $\left.\varepsilon_{\mathrm{r}}=4.5\right)$, Taconic TLY-5 $\left(\varepsilon_{\mathrm{r}}=2.2\right)$, Alumina $(96 \%)\left(\varepsilon_{\mathrm{r}}=9.4\right)$, Teflon (PTFE) $\left(\varepsilon_{\mathrm{r}}=2.08\right)$, Arlon AD5 $\left(\varepsilon_{\mathrm{r}}=5.1\right)$ dielectric materials are used as the substrate. The Performance of the microstrip antenna depends on its dimension. Depending on the dimension the operating frequency, radiation efficiency, directivity, return loss and other related parameters are also influenced.

Generally any microstrip patch antenna must have the considerations such as length, width, and efficiency. The length of the microstrip patch antenna is generally calculated by using the formula given in equation 1 [1].

$$
L=\frac{1}{2 f_{r} \sqrt{\varepsilon_{\text {eff }}} \sqrt{\mu_{0} \varepsilon_{0}}}-2 \Delta L
$$

The width of the microstrip patch antenna is given by the equation 2 [1].

$$
\mathrm{W}=\frac{1}{2 f_{\mathrm{r}} \sqrt{s_{0} \mu_{0}}} \mathrm{x} \sqrt{\frac{2}{s_{\mathrm{X}}+1}}
$$


The efficiency microstrip patch antenna is obtained by using equation 3 [1].

$$
\varepsilon_{\text {eff }}=\frac{\varepsilon_{r}+1}{2}+\frac{\varepsilon_{r}-1}{2 \sqrt{1+12^{h} / w}}
$$

Where, $\lambda$ is the wave length, $f_{r}$ (in $\mathrm{Hz}$ ) is the resonant frequency; $L$ and $W$ are the length and width of the patch element, in $\mathrm{cm}$, respectively and $\varepsilon_{r}$ is the relative dielectric constant.

The proposed structure of the antenna is shown in Figure 1. The antenna is simulated on two FR-4 substrates with a dielectric constant of 4.4 and a loss tangent of 0.02 . The thickness of the substrate is $0.7 \mathrm{~cm}$. The size of the antenna is $4.94 \times 4.19 \mathrm{~cm}^{2}$

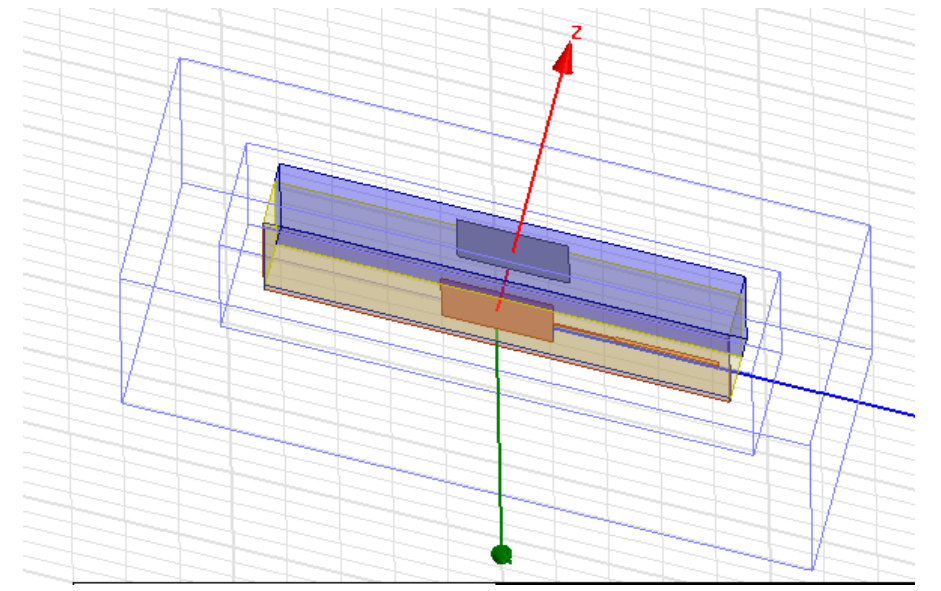

Figure 1. Proposed microstrip patch antenna design

The patch can be fed with edge feeding to the patch of the antenna directly. The dimensions of stacked patch shown in Figure 1 are $\mathrm{L}=4.94 \mathrm{~cm}, \mathrm{~W}=4.19 \mathrm{~cm}$ which are designed at operating frequency $2.4 \mathrm{GHz}$.

\section{Results and Analysis}

The proposed antenna is simulated using HFSS software. The analysis on results obtained for different parameters of proposed antenna is as follows:

\subsection{Return loss}

Return loss is a measure of the effectiveness of power delivery from a transmission line to a load such as an antenna. It is a logarithmic ratio measured in $\mathrm{dB}$ that compares the reflected power by the antenna to the power fed into the antenna from the transmission line. Return loss commonly expressed as a negative number. The smaller the return loss, the lesser energy is reflected. The proposed antenna is simulated using HFSS software. Return loss curve of proposed antenna is shown in Figure 2. The return loss of $36.1 \mathrm{~dB}$ is obtained at center frequency of $2.35 \mathrm{GHz}$ which is used for wireless LAN, Bluetooth applications. 
International Journal of Energy, Information and Communications

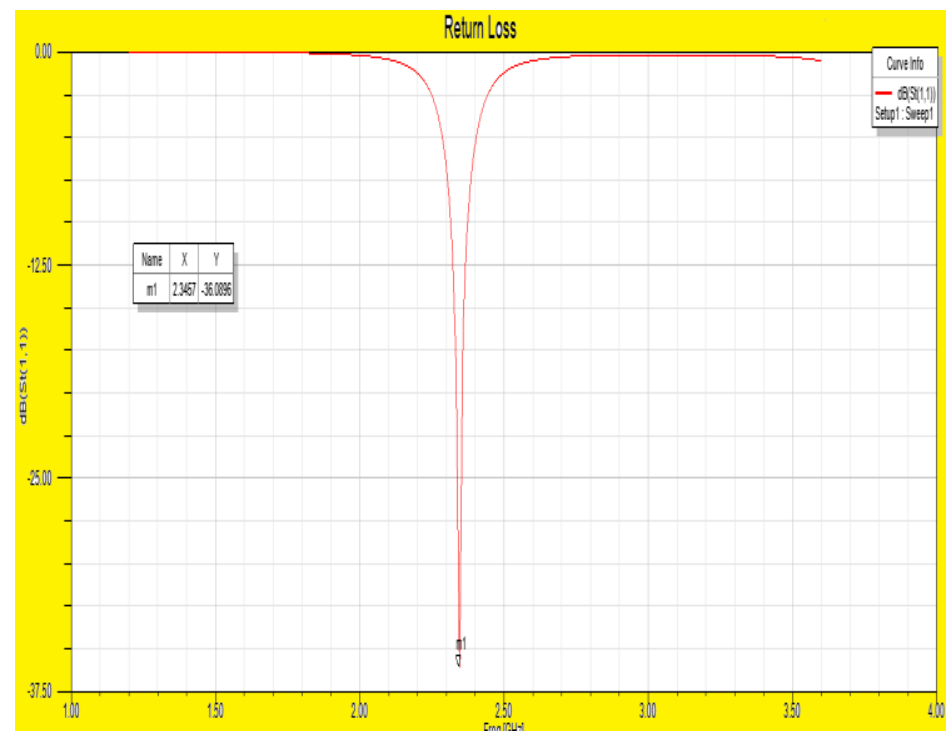

Figure 2. Return loss curve of proposed antenna

\subsection{Gain}

Antenna gain is the ratio of radiation intensity of a practical antenna in a given direction to the radiation intensity that would be produced by an isotropic antenna. It describes the amount of power transmitted (radiated) in the given direction to that of an isotropic antenna. In this design the gain up to $8.6 \mathrm{db}$ is obtained. That means proposed antenna radiates more amount of power in desired direction. For any micro strip patch antenna $6 \mathrm{db}$ above gain is acceptable. The 2D and 3D gain plots of proposed antenna are shown in below Figure 3 and Figure 4.

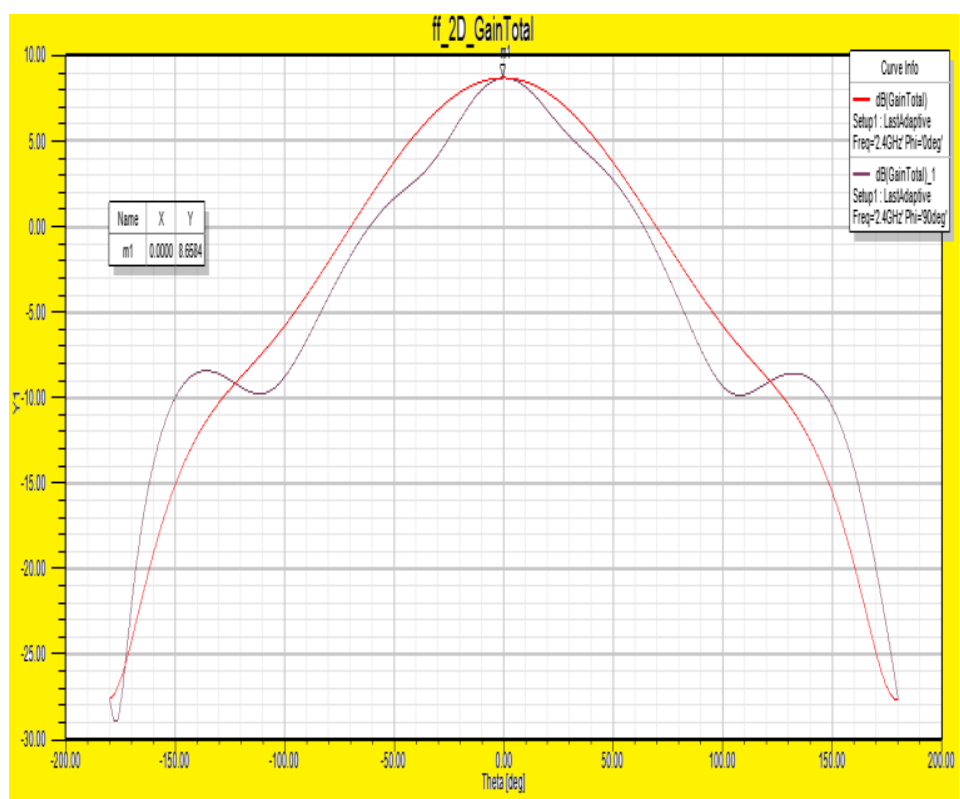

Figure 3. The 2D gain plot of proposed antenna 


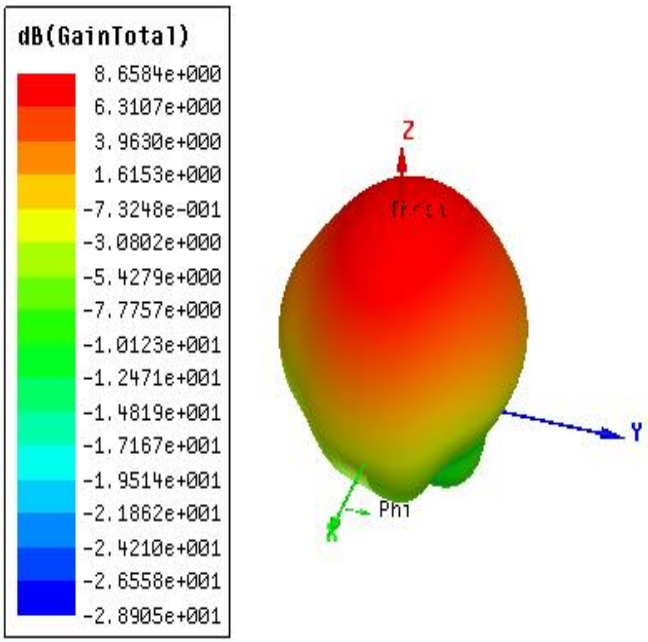

Figure 4. The 3D gain plot of proposed antenna

\subsection{VSWR}

The VSWR is a measure of the impedance mismatch between the antenna and the transmission line connected to it. The higher the VSWR, the greater is the mismatch and hence more power is reflected back to the source. The VSWR of unity means that no power is being reflected back to the source. A VSWR of $2 \mathrm{~dB}$ is considered excellent in most practical applications. The VSWR for the proposed antenna is less than the $1 \mathrm{~dB}$. The Figure 5 shows the VSWR curve of proposed antenna.

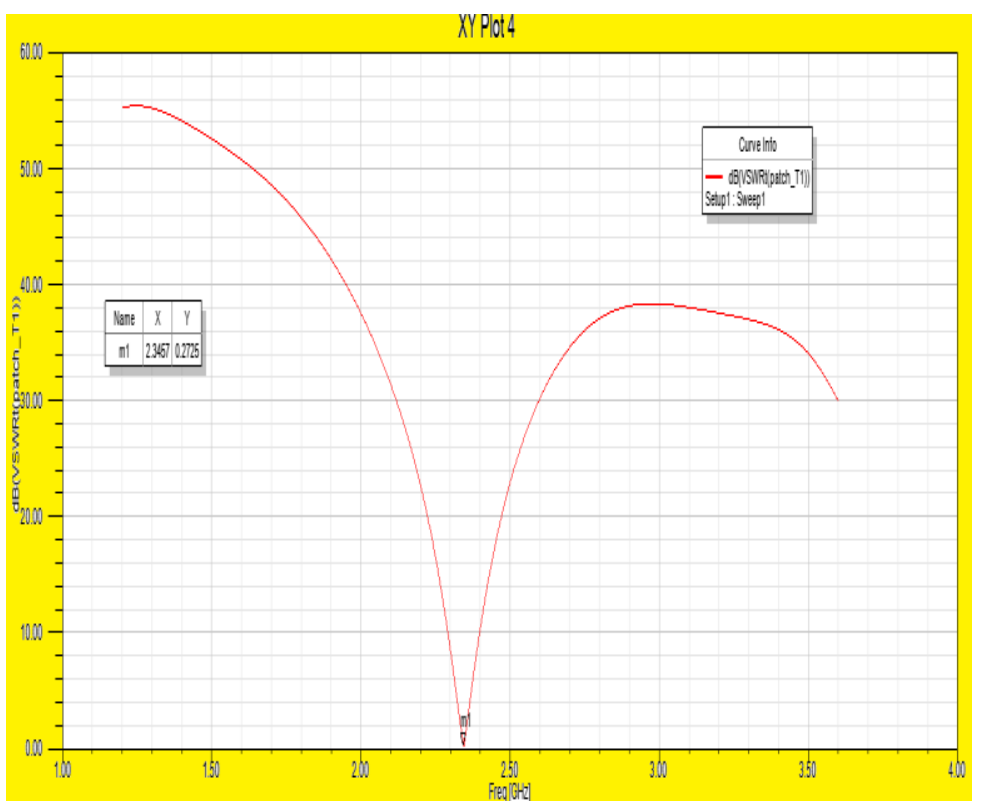

Figure 5. VSWR curve of proposed antenna 


\subsection{Radiation pattern}

Radiation pattern is a graphical representation of the antenna radiation properties as a function of spherical coordinates in desired direction. The proposed antenna is simulated for obtaining three different types of radiation patterns such as gain at total, gain at theta and gain at pi. The Figure 6, 7, and 8 shows the radiation pattern for gain at total, gain at pi, and gain at theta respectively.

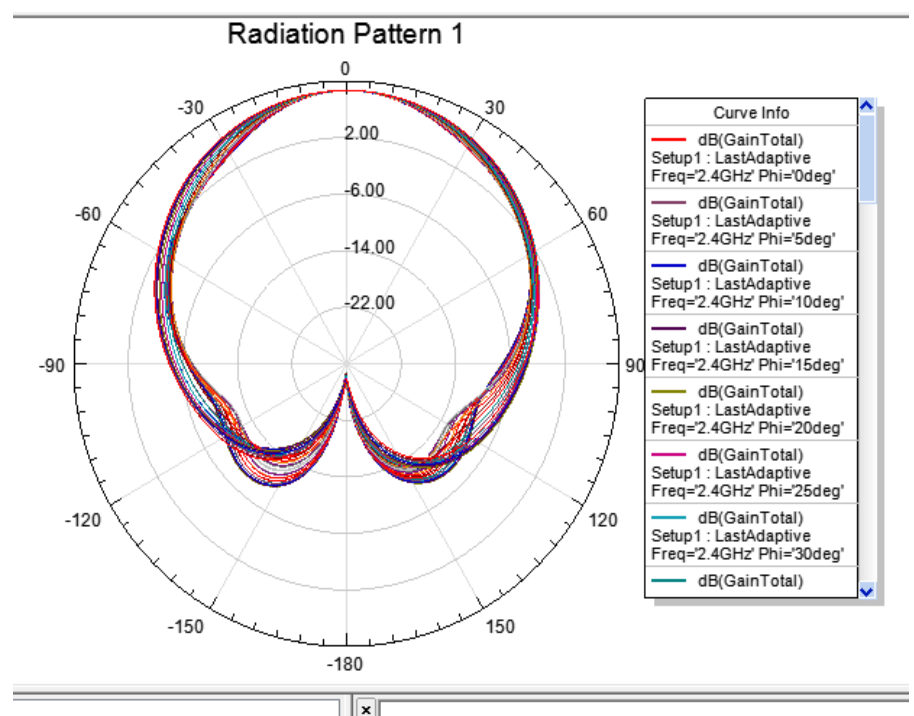

Figure 6. Gain at total

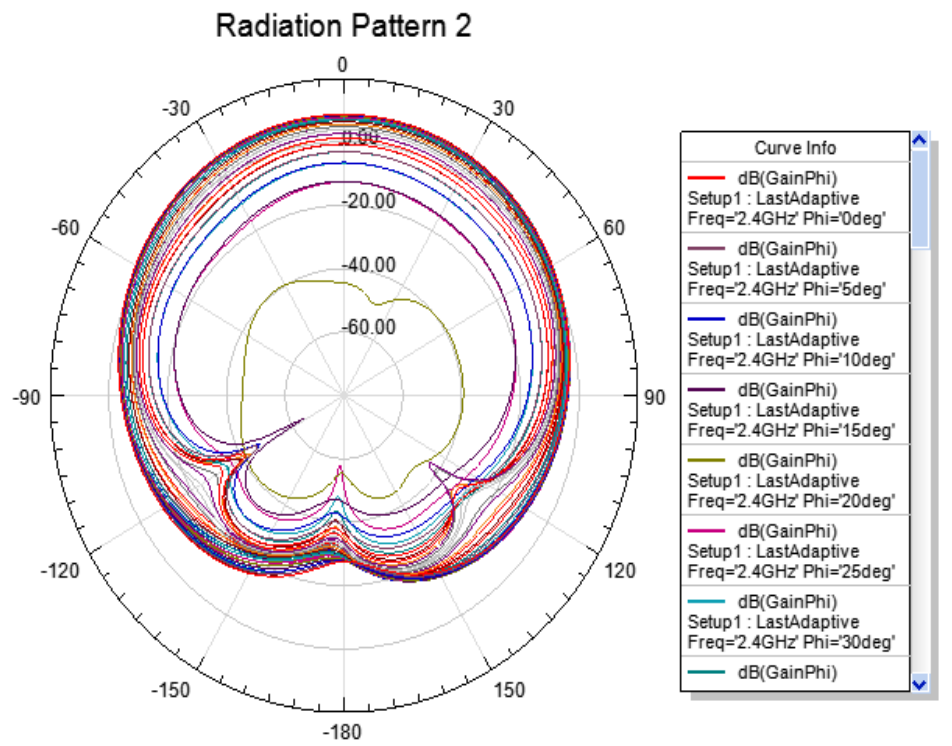

Figure 7. Gain at pi 


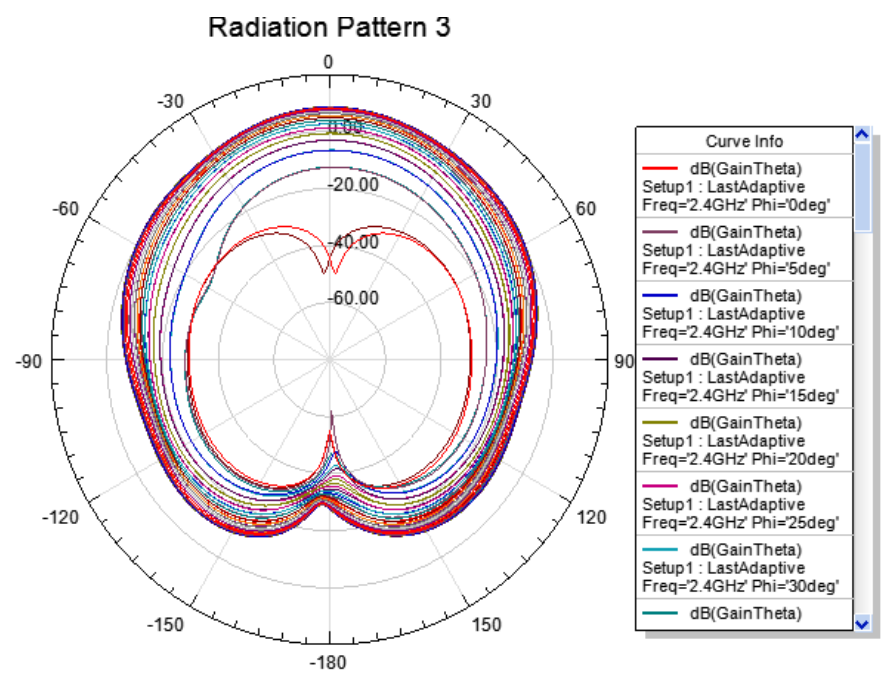

Figure 8. Gain at theta

\subsection{E-field pattern}

An electric field can be visualized by drawing field lines, which indicate both magnitude and direction of the field. Field lines start on positive charge and end on negative charge. The direction of the field line at a point is the direction of the field at that point. The relative magnitude of the electric field is proportional to the density of the field lines. The E-field pattern of proposed antenna is shown in Figure 9.

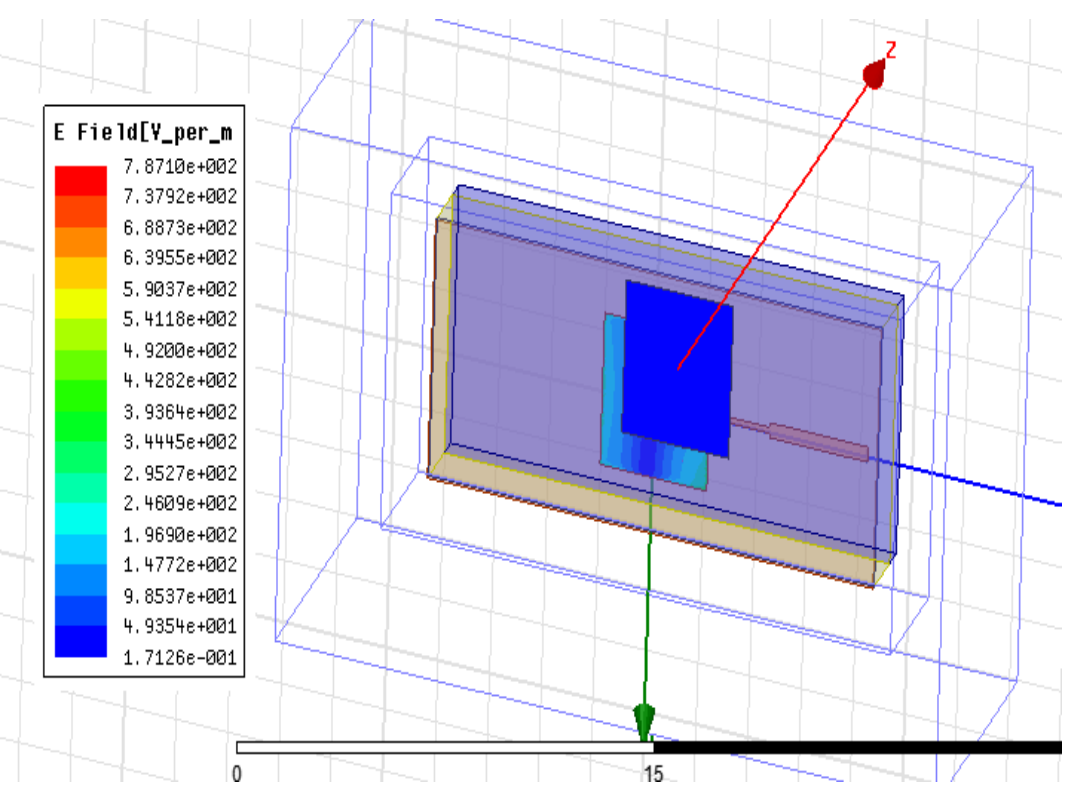

Figure 9. E-field pattern of proposed antenna

\subsection{H-field Pattern:}

In the case of the same linearly polarized antenna, this is the plane containing the magnetic field vector and the direction of maximum radiation. The magnetic field or " $\mathrm{H}$ " plane lies at a right angle to the "E" plane. For a vertically-polarized antenna, the H-plane usually coincides 
with the horizontal/azimuth plane. For a horizontally-polarized antenna, the H-plane usually coincides with the vertical/elevation plane. The H-field pattern of proposed antenna is shown in Figure 10.

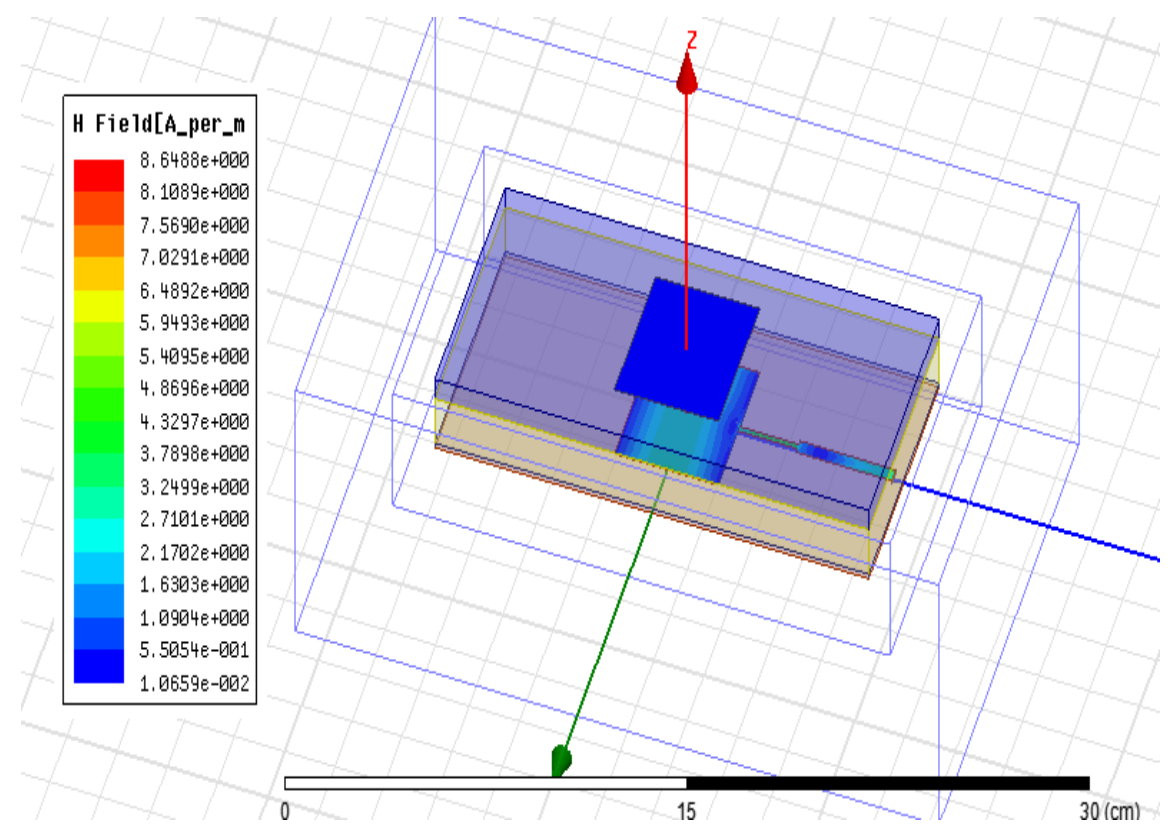

Figure 10. H-field pattern of proposed antenna

\section{Conclusion}

In this paper a novel double layer microstrip stacked patch antenna with edge feed is proposed and investigated. The simulation results for return loss, gain, input impedance, radiation pattern and VSWR, axial ratio is presented. Better results can be obtained by increasing the number of substrates between the radiating elements. Proposed antenna is more suitable for wireless LAN and Bluetooth applications.

\section{Acknowledgements}

The authors would like to the management of St. Ann's College of Engineering and Technology and the Department of Electronics and Communication Engineering for their continuous support and encouragement during this work.

\section{References}

[1] K. -L. Wong, "Compact and Broadband Microstrip Antennas", Wiley and Sons, Inc., New York, (2002), pp. $1,12-15$.

[2] V. Gupta and N. Gupta, "Gain and Bandwidth Enhancement in Compact Microstrip Antenna", International Union of Radio Science, Proceedings, (2005).

[3] T. S. P. See and Z. N. Chen, "Design of Broadband Dual-Polarization Stacked Microstrip Antennas for Bluetooth Applications", Proceedings of the 8th IEEE International Conference on Communication Systems, ICCS 2002, (2002), pp. 1174-1178.

[4] N. Boisbouvier, F. L. Bolzer and A. Louzir, "A Compact Radiation Pattern Diversity Antenna for WLAN Applications”, IEEE AP-S Int. Symp. Dig., vol. 4, (2002), pp. 64-67. 
[5] R. Q. Lee and K. F. Lee, "Experimental study of the two-layer electromagnetically coupled Rectangular patch antenna", IEEE Trans. Antennas and Propagation, vol. 38, (1990) August, pp. 1298-1302.

[6] R. L. Yadava and B. R. Vishvakarma, "Analysis of electromagnetically coupled two-layer elliptical microstrip stacked antennas", International Journal of Electronics, vol. 87, no. 8, (2000), pp. 981-993.

[7] D. M. Pozar and D. H. Schaubert, "Microstrip antennas: the analysis and design of microstrip antennas and arrays", IEEE Press, (1995).

[8] S. Egashira and E. Nishiyama, "Stacked microstrip antenna with wide bandwidth and high gain", IEEE Trans-actions on Antennas and Propagation (USA), vol. 44, no. 11, (1996), pp. 1533-1534.

[9] R. L. Li, G. DeJean, K. Lim, M. M. Tentzeris and J. Laskar, "Design of Compact Stacked-Patch Antennas in LTCC multilayer packaging modules for Wireless Applications".

[10] A. B. Nandgaonkar and S. B. Deosarkar, "Broadband stacked patch antenna for Bluetooth applications", Journal of Microwaves, Optoelectronics and Electromagnetic Application, vol. 8, no. 1, (2009), pp. 1-5.

\section{Authors}

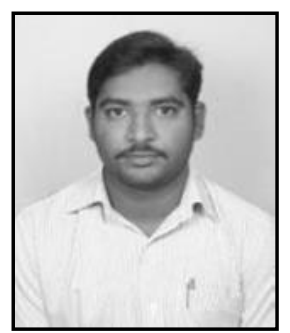

J. Chandrasekhar Rao was born in India, A.P in 1985. He received his B. Tech, M. Tech degrees in ECE. He is currently working as Assistant professor in ECE department of St. Ann's College of Engineering and Technology. He has 4 national conference papers, and 4 international journal publications. His research interests include microstrip antennas, image processing and microprocessors.

A. K. Chaitanya was born in 1990 at Guntur District, Andhra Pradesh state, India. He Graduated in Electronics and Communication Engineering from Chirala Engineering College, JNTU kakinada, Chirala. Presently He is pursuing his M. Tech in Communication and Radar systems in Koneru Lakshmaiah University, vaddeswaram, A.P., India. 
International Journal of Energy, Information and Communications Vol.4, Issue 5 (2013) 